\title{
Problems of Learning through MOOCs for Local University Students and Countermeasures
}

\author{
Jiao $\mathrm{Li}^{1, \text { a }}$, Wei Wang ${ }^{2, \mathrm{~b}}$ \\ ${ }^{1}$ School of Literature , JiLin Agricultural University, Changchun 130118, China; \\ ${ }^{2}$ P.E.Department, JiLin Agricultural University, Changchun 130118, China. \\ a30388553@qq.com, ${ }^{\mathrm{b}}$ 64468728@qq.com
}

Keywords: MOOC; Study; Local Universities; Undergraduates

\begin{abstract}
This research investigated the status quo of students' study of MOOCs in local universities. The results show that: local college students' study of MOOCs are primarily driven by their interests and the requirement of necessary expertise; selection of courses is subject to the influence of well-known schools, teachers' decisions on this issue, course contents and credit requirements; most MOOCs learners are characterized by incomplete learning experience, short learning time, insufficient participation in interaction, and strong demands of tutorship. this paper proposes a systematically planned introduction of MOOCs On this basis; improvement of support services for study of MOOCs; enhancement of teachers' enthusiasm in participating in MOOCs; the strategy of integrating online and offline teaching and interaction.
\end{abstract}

\section{Introduction}

The ideology and application of MOOCs has brought fundamental reform to China's higher education with the import of new highly-effective resources into the personnel training programs. Chinese local colleges and universities are featured with large number of students, high teaching cost as well as less teaching resources and with the strong demands for MOOCs. In order to understand the status quo of local college students' study of MOOCs and encourage college students to accept and use MOOCs, this research investigated the status quo of students' study of MOOCs in local universities.

MOOCs have brought the new atmosphere in some aspects, such as teaching reform of colleges and universities education in our country. Especially, It brought new resources to the local universities' personnel training. Learners of MOOCs in China are mainly university students. And local universities generally feature large numbers of students, high cost of teaching, and less teaching resources, which results in stronger demands for MOOCs. In order to understand the status quo of local college students' study of MOOCs and encourage college students to accept and use MOOCs, this research investigated the status quo of students’ study of MOOCs in local universities.

\section{Research design and implementation}

\section{Sample situation overview}

From the perspective of the gender of samples, the distribution is relatively balanced. While from the viewpoint of grades, the respondents are mostly undergraduates which accounted for more than 96.81\% with postgraduate accounting for only 3.19\%. Judging from the specialty background of respondents, the results showed a widespread distribution. Literature and management together 
accounted for $42.55 \%$; science and technology accounted to $30.85 \%$; law, agriculture, pedagogy, and history accounted for a relatively smaller proportion of $26.6 \%$.

\section{Analysis and discussion of investigation results}

Approaches and motives of participating in MOOCs. At present, local college students have many channels to join MOOC. Schools, teachers, classmates, friends and the Internet are among the major channels, of which schools as the most important channel accounted for $59.57 \%$. This is closely related to the development of MOOC and enhanced introduction and extension of MOOC of local colleges and universities. Two-thirds of the local colleges involved in this investigation have already introduced MOOC and carried out the teaching of selective and required courses in the form of online courses or blended teaching. This directly promoted the application of MOOCs in local colleges and universities as well as local college students' study of MOOCs.

In terms of motivation, hobbies, requirements of specialty study, schools and teachers' recommendations as well as obtaining credits are among the major reasons for study of MOOCs. Meanwhile, respondents' selection of courses is a contributor to such motives. They tend to choose courses related to their hobbies and majors.

Status of Study and Completion. Learners of local colleges primarily participating in domestic MOOCs accounts for $95.74 \%$. While the number of learners studying foreign MOOCs is relatively smaller and accounts for $31.91 \%$, and these MOOCs learners only study a small number of courses, there is over $80 \%$ of the learners selecting 1-3 courses to study these MOOCs learners only study a small number courses. Over $80 \%$ of the learners study 1-3 courses. The most frequently used MOOC platforms are: Chinese University MOOC (47.87\%), UOOC (34.04\%), Baidu Chuanke (11.7\%) and Zhihuishu (9.2\%). In contrast, learners of three major foreign MOOC platforms account for less than $10 \%$. Main considerations of MOOCs learners when choosing courses are: courses of famous schools and teachers, course contents and credits certification.

As for the completion of MOOCs, only a few learners have complete learning experiences and $65.96 \%$ of the respondents quit halfway. Over $80 \%$ of the learners study less than 3 courses.They believe boring contents, unattractive presentation of teachers, a lack of willpower, incapability of adapting to online learning and a lack of channels to get answers to their questions are among the major difficulties. This reflects that learners are unsatisfied with current learning resources in MOOCs. $50 \%$ of the learners need guidance in part of the courses, and $16.67 \%$ of them take relevant guidance necessary in the study of MOOCs. Therefore, local college students are generally characterized by poor autonomous learning ability and strong demands for tutorship.

Characteristics of learning behaviors. In terms of learning time, local college learners' average learning time is usually short. Nearly half of the learners study MOOCs for less than 1 hour per week with the learning time between 1-4 hours, accounting for $41.49 \%$ and over 4 hours accounting for $12.77 \%$. To students from local universities, MOOCs is now only a complement to the traditional higher education.

Most MOOCs learners are casual, while studying in the course. Only about $10 \%$ learners have definite study plans and most of the learners occasionally have study plans. During the learning process, learners rarely participate in learning interactions. $60.64 \%$ learners don't participate in learning interactions and only $2.13 \%$ of them are highly active, which suggests that learners prefer to watch videos alone in MOOCs study.

Evaluation of learning experience and willingness to pay. This research shows that most of the learners hold more positive attitudes towards MOOCs. To $17.02 \%$ of the learners, MOOCs is very helpful, while $68.09 \%$ learners think it's of certain help. In the rating of satisfaction with MOOCs, the 
respondents gave an average score of 7.03 (10 points), which suggests that they're basically satisfied with MOOCs. According to learners, the main problems are that: students are unable to communicate with teachers; types of courses are limited; curriculum is boring; lack of tutorship. As for the willingness to pay, most learners can accept certain expenses. Statistic analysis shows that $43 \%$ of the learners agree to pay no more than 10 yuan, while $27.66 \%$ of them accept costs between $10-50$ yuan.

\section{Guidance strategies in MOOC study}

Introduction of MOOCs should be systematically planned. The construction of MOOCs in China is still in an early stage which features a lack of systems in curriculum construction and scattered resources. Quality MOOCs are products of elite universities which do not completely applied to the necessity of universities' personnel training. Different local universities have different learning demands and digital learning capacity.[1] Therefore, they may not necessarily match the training needs of local colleges and local college students' learning needs and e-learning capabilities. Consequently, local colleges and universities should beforehand assess the consistency between their professional personnel training objectives, teaching goals of their curriculum and the MOOCs to be introduced to make MOOCs supplies more consistent with the demands; Establish and improve relevant mechanisms to achieve selective introduction of MOOCs, planed usage of MOOCs, guidance in MOOK study, and secure credits certification, incorporate MOOCs into the personnel training system step by step for the real landing of MOOCs in local colleges and universities.

Improving the MOOC's learning support services. In addition to online video courses, MOOCs should also provide students with guidance, mentoring, assignments, assessment and learning support services at all stages. This survey shows local college students' strong needs for guidance, which exposes the lack of learning support services in MOOC. MOOC's learning support services can be provided both online and offline. Due to constraints in faculty, forms, space and time, online learning support services are very limited and certainly cannot meet the needs of students, while offline learning support services have more space for development. When conducting MOOC teaching, local colleges and universities should establish a set of learning support services, actively carry out various forms of multi-level offline teaching and learning activities including course screening and recommendations, tutorials and mentoring to timely answer students' questions and improve the learning effect.

Enhancing the enthusiasm of teachers in participating in MOOC. In the teaching of MOOC, the role of teachers has changed into a mentor with monitoring responsibilities. They're primarily responsible for the selection and supply of learning resources, progress monitoring, guidance on course contents and study, as well as evaluation of learning effect.[2] This survey showed that teachers are very influential in guiding MOOC learners, but the effect is not ideal, which could be attributed to low enthusiasm and degree of teachers' participating in MOOCs. While introducing MOOCs, local universities should formulate corresponding management policies; encourage the teachers to try modes like MOOC, flipped classroom, and mixed teaching; provide teachers with more external supports and consider corresponding measures like moderating effect. [3]

Integrating online and offline teaching interactions. Strong interactivity is one of the outstanding characteristics of MOOC. However, according to this investigation, the status of MOOC learners' interaction is not ideal. Most students are reluctant to participate in in-depth interaction. This may be related to a lack of interaction design. Therefore, during the teaching of MOOCs, local universities should make full use of offline teaching interactions; organize activities such as team collaboration 
and interactive mentoring; integrate online and offline resources to arouse the enthusiasm of learners to participate in interactive learning and enhance the stability and durability of online learning.

\section{Summary}

The emergence and development of MOOCs have created new opportunities for education reforms in local colleges and useful channels to enhance the quality of talent training and improve talent training modes. With educational authorities' vigorous promotion and active introduction of local universities, MOOC has gradually become a part of local universities' personnel training systems and achieved preliminary results in helping local college to cultivate talents. However, imperfect construction of MOOC itself, local universities' unfinished introduction of MOOC, and local college students' superficial understanding of MOOC have resulted in a low degree of overall cognition among local college students, a small learner base, short learning time, and incomplete learning experience.

During the survey of MOOC learners from local colleges, it was found that local college students' study of MOOC is primarily driven by their interests and the requirement of speciality study; well-known schools and teachers' decisions on setting up new courses, course contents and credit requirements are main influencing factors of course selection. Learners are generally facing problems like insufficient participation in interaction, poor self-study abilities and strong demands of tutorship. Evidently, MOOCs in local colleges and universities still have much room for future development. Educational managers need to develop relevant promotion tactics according to their situations and specific needs of personnel training from the perspectives of planned introduction of MOOC, learning support services, enthusiasm of teachers in participating in MOOCs as well as the integration of online and offline teaching to promote the development and enrich the functions of MOOCs.

\section{References}

[1]Zhang Changhai,Jiao Jianli,A Study on the Influencing Factors in Local University Undergraduates'Acceptance of MOOCs.China Academic Journal Electronic Publishing House.2015.6:65.

[2]Wu Junqi, Zhao Chengling, Xu Xiong, The Comparative Analysis between Online Teaching and the In-class Teaching.China Academic Journal Electronic Publishing House.2000.6:13.

[3]Fang Xu,Yang Gaixue, Research on the Factors of College Teachers' Behavior Intention for MOOC Teaching.China Academic Journal Electronic Publishing House.2016.4:75.

[4]Yuan Songhe, Liu Xuan, Status and Common Problems of MOOC Practice in China's Universities, Modern Distance Education Research.2014.4:3-12.

[5]Liu Yang,Huang Zhenzhong,Li Manli,A Report MOOCs Participation in China, Tsinghua Journal of Education,2013.8:27-34.

[6]Yu Xin,Lu Honglei,Research on Influence Factors of Learners Adopting MOOC:Based on User Surveys of Tsinghua University’s “Online School”, Modern Distance Education,2014.5:3-8. 